\title{
Crossing Contexts: Applying a System for Collaborative Investigation of School Space to Inform Design Decisions in Contrasting Settings
}

\author{
Pamela Woolner ${ }^{1, *}$ and Paula Cardellino ${ }^{2}$ (D) \\ 1 School of Education Communication and Language Sciences, Newcastle University, Newcastle NE1 7RU, UK \\ 2 Facultad de Arquitectura, Universidad ORT Uruguay, Montevideo 11300, Uruguay; cardellino@ort.edu.uy \\ * Correspondence: Pamela.Woolner@newcastle.ac.uk
}

Citation: Woolner, P.; Cardellino, P. Crossing Contexts: Applying a System for Collaborative Investigation of School Space to Inform Design Decisions in Contrasting Settings. Buildings 2021, 11, 496. https://doi.org/10.3390/ buildings 11110496

Academic Editor: Francesco Nocera

Received: 1 September 2021

Accepted: 7 October 2021

Published: 21 October 2021

Publisher's Note: MDPI stays neutral with regard to jurisdictional claims in published maps and institutional affiliations.

Copyright: (C) 2021 by the authors Licensee MDPI, Basel, Switzerland. This article is an open access article distributed under the terms and conditions of the Creative Commons Attribution (CC BY) license (https:// creativecommons.org/licenses/by/ $4.0 /)$.

\begin{abstract}
This paper presents a system for participatory appraisal and idea generation by a school's users to enable interdisciplinary collaboration between educators and architects, producing school designs appropriate to the needs of the school at the time and into the future. Our uses of this system in two contrasting educational settings in England and in Uruguay are described. We show how the visual-spatial activities supported the educators to consider education in spatial terms, build a shared understanding and produce representations that could be used to convey ideas to architects and designers. Given that participation and cross-disciplinary collaboration in school design is known to be challenging, but vital, we consider the features of our approach that enabled its success and make it viable on each and every occasion of school design or redesign. Further, addressing the critiques of attempted international transfer of architectural designs, educational policies, practices and buildings, we argue that our system avoids these problems through seeking to transfer not a project but the means to enable participation in a project.
\end{abstract}

Keywords: school design; participatory design; knowledge transfer; education; architecture

\section{Introduction}

In our increasingly connected world, the transfer of knowledge, understanding and ideas seems to promise effectiveness and efficiency. However, research into school design, and to differing extents within the underpinning disciplines of education and architecture, demonstrate the evident disadvantages of uncritical transfer of policies, designs, and buildings. In this introductory section, we first discuss these issues, within and across architecture and education. Following this and responding to the problems we outline of an over-emphasis on generalized approaches to particular situations, we briefly consider the challenges of participatory approaches to designing tailored solutions. This is particularly applied to any attempt to involve educational practitioners in meaningful collaboration with architects and designers to produce school spaces that support the practices and values of that specific school community, currently and into the future. In Sections 2 and 3 of the paper, we present our contribution of a system for developing shared understandings of pedagogical and spatial needs and possibilities to inform a school design process, together with the two contrasting cultural contexts in which we have used it. Finally, in discussing its performance and apparent success, we examine the aspects of our contribution that enable it to travel, as well as to withstand the challenges of participation that we identify.

\subsection{Troubles with Transfer}

\subsubsection{Architecture}

The transfer of knowledge or ideas in architecture and design is common practice [1]. The idea of precedent has been used in design, and it is seen by designers as an important part of their knowledge upon which they are able to draw in a 'designerly' way [2]. A key 
design characteristic of precedents is the fact that they can demonstrate different ways of doing things in design. Throughout the history of professional design such knowledge has played an important role.

At times, however transferring knowledge between nations and regions within the architectural arena has shown faults. For example, the case of the Modern Movement in architecture during 1950s and 1960s and its implementation in different contexts and cultures. One of the central objectives of this style of architecture was to meet the need for public housing during the post-war era. Following design precepts of modernist architect Le Corbusier in Europe, several public housing projects in the United States were built in a stripped-down modernist style. Several authors suggest that the insensitivity of the modernist design to the needs of residents and the incompatibility between highrise housing solutions and social housing were to blame for the decline of these type of projects in this country. An emblematic example of this was the Pruitt-Igoe development in Missouri, United States, that since its demolition has remained as a symbol of the failure of the Modern Movement [3].

From a construction point of view, transfer of ideas has also experienced drawbacks. For example, materials and finishes developed in United States, such as the 'curtain wall', were used in the 1950s in regions of Latin-America with no real consideration for the local climate and a lack of technology to manufacture the product [4]. As one architect stated 'The region was not technologically ready to take on the curtain wall'. Eager to exhibit the building's operating mechanisms, especially the bearing structure, local architects used alternative finishes to resemble the curtain wall solution, that ended up being not fit for purpose.

Considering the architecture of education, school buildings, wherever constructed, generally mirror contemporary architecture rather than educational imaginaries, often leading to the reproduction of the industrial model of classrooms. This indicates little recognition of the significance of context for any particular school. Some notable exceptions to this are Reggio Emilio, Montessori and Dewey, where the designs are derived from particular educational philosophies [5-7].

An emergent theme is the significance of the design process [8,9]. Whyte and Cardellino [10] analyzed the role of visual representations in school design. Overall, the study tracked the political, cultural, and aesthetic judgments made around visual representations within the English Building Schools for the Future (BSF) programme (2003-2010). The conclusion highlights the significant role architects play in developing discourses and images associated with school design. There are pressures that exert an influence on the design-visual representations are used to show the desired outputs, convey precedents and exemplars, and develop the professional attitudes and approaches through professional activities. The visual representations circulate design ideas across context and enroll stakeholders into a broad set of ideals. This circulation and enrolment can be both intended and unintended, for example as elements of the user brief become quite literally interpreted in an architect's bid; or through different interpretations of the images shown as precedents and exemplars.

\subsubsection{Education}

In some contrast to the perspective from architecture, history and more recent experience within education demonstrate the flaws in transferring ideas between nations and cultures to influence policy or practice. Scholars who practice cross-national comparisons within education, and in social science more generally, have long engaged in nuanced and careful discussion about exactly how studies of social phenomena across cultures should be conducted and understood [11]. Alexander's immensely detailed study of primary schooling across a number of contrasting national contexts [12] is similarly careful to delineate the conclusions that should be drawn or the uses to which his research can be put: 
Though there are undoubted cross-cultural continuities and indeed universals in educational thinking and practice, no decision or action which one observes in a particular classroom, and no educational policy, can be properly understood except by reference to the web of inherited ideas and values, habits and customs, institutions and world views which make one country, or one region, or one group, distinct from another. ([12], p. 5)

Yet, historically policies, curricula, and sometimes whole educational systems have been transferred, typically from more economically and politically powerful nations to those they colonized [13], and this trend continues in, for example, moves towards a 'learner centred' approach to schooling in sub-Saharan Africa in the 1990s [14] and recent curriculum reform attempts in Saudi Arabia mathematics education [15]. The popularity of international education league tables, based on assessments such as the Programme for International Student Assessment (PISA), Trends in International Mathematics and Science Study (TIMSS) and Progress in International Reading Literacy Study (PIRLS), can particularly encourage simplistic comparisons between culturally very distinct systems and attempted adoptions of aspects of practice or policy, as governments seek to emulate the approaches of countries that are successful [16,17].

To illustrate how this phenomenon occurs, and the consequences of 'borrowing' [18], we turn to a recent example in the UK educational context. This is the drive to adopt a so-called 'mastery' approach to primary mathematics since this approach is seen as underpinning the success of Shanghai and Singapore in the international league tables. Clapham and Vickers are critical of how the challenges of 'implementing and internalising borrowed policy', that conflicts quite explicitly with many aspects of existing educational organisation and practice, are passed down from policy-makers, who do not appreciate the complexity, to practitioners who are not positioned to enact the 'root-and-branch reorientation of systems and practices' ([18], p. 802).

Relating to school architecture, specifically, there is similarly a suspicion of ill-judged attempted transfer, nonetheless combined with continued attempts to reproduce design ideas across the globe. Historically, a determination to build schools appropriate for the local culture and climate is discussed in Uduku's presentation of the Nigerian 'Unity Schools' [19], as well as the lingering influence of missionary provision on assumptions about the necessity of physical space and material accommodation for technology subjects.

More recently, Wood found school principals of new builds in England explaining design decisions by referring to "Australia and Scandinavia" or "Australia and America", leading him to remark that buildings, despite their physical stability, have a 'surprising capacity for travel' ([20], p. 476). He explains this tendency through noting the 'seductive' representations of buildings in plans and photographs which are easily transported, reflecting our discussion of visual representations in architecture in the previous section. Wood's central argument, however, paralleling the critique of curricular transfer, is that importation of a school design developed elsewhere for particular cultural and historical reasons will produce contradictions and mismatches. Although the desire to take systems, practices and indeed buildings that produce success in a specific context and generalize across contexts continues to be attractive, there is plenty of warning in education of the problems that ensue at various scales, from between school influences to international borrowing.

\subsection{Perils of Participation}

If searching for general solutions and standardised designs to apply to school construction is problematic, as the above consideration of international transfer suggests, we need then to consider how we design for local needs. An impetus for rejecting attempted generalisation in school design is also to be found in recent research of the impact of space on learning. This body of evidence shows that, once basic environmental comfort levels have been achieved, the success of a spatial design will be mainly determined by how well it accommodates the activities of the occupying school community and aligns with the values and ethos that underpin those educational practices [21-23]. 
The means to achieve this fit of design and use which is usually suggested within this literature is the participation of school users in the planning and designing process $[9,24,25]$. However, while examples exist of successful collaboration of school communities with architects and designers [26-28] there is also plentiful description and discussion of the challenges of participation, and of the failed school designs where participation in the design process does not occur or is not successful [22,29]. Here it is just necessary to briefly mention these acknowledged challenges of participation, which center on finding the time to collaborate and to plan, both towards the design and for any changes to practice that will be required to make the new design work [25,30,31]. Professional development opportunities to enable teachers to understand and use their spaces more effectively are also suggested $[32,33]$ as is the use of relevant external expertise, in the form of facilitators to guide the participatory process [34]. An overarching issue is the apparent necessity of enacting this collaborative engagement with school space within each and every school community where change, rebuilding or redesigning is attempted [28] (pp. 398-399), with the considerable demands on people's time and energy that this brings, as well as the financial implications of this commitment.

\section{Materials and Methods: Our System}

Our system was developed to support a school community to review their school premises, considering the suitability of the building for their current practices and also thinking about new possibilities for the design and use of their space. Fundamental to the approach is the understanding, not surprising to architects and now quite established within research of educational space, that the design and use of the space are inevitably interlinked (see e.g., $[35,36])$. Thus, the totality of the learning environment experienced by students is produced by the mix of material, social and organizational elements that the school provides; central to the success of this environment is the alignment between these different aspects [23,25].

The system we present and discuss here is intended to support a review involving many different people, which could include students and staff with a range of teaching, leadership, and other roles, so needs to accommodate a diverse range of background interests and knowledge to ensure that many views are fully represented and can contribute to proposed solutions. It is based on a series of activities where participants work with visual-spatial materials, producing items that can then be used to mediate conversations about specific aspects of their existing premises and provoke discussions about physical spaces and educational activities. The use of visual materials and products that are literally on the table for all participants to see, discuss and contribute to, facilitates the development of a collective understanding, which is important in the context of developing a single school environment. These activities draw on understandings and practices that have developed in social science where approaches broadly defined as 'visual methods' have been found to support engagement with participants, provide them with more opportunities to influence a process and enable them to convey ideas that might be difficult to articulate, as well as bringing to light different information from investigations relying on words alone [37-39]. Two of the three activities have been used as part of consultations with school communities about their educational environment [29,40,41] and all three activities share features with approaches that have been proposed and developed to the exploration of users' experiences of school space [24,42].

In planning the progression through the activities, we accepted that users of a space will first want to consider their existing environment, but we wanted to move them beyond the salience of the current space and its use to consider alternatives. Therefore, we began with an activity to share users' experiences of their existing school space, then we used an activity with photographs of learning spaces to open discussion about the relationship between learning and space, before moving onto an activity focused on designing solutions to problems identified within the existing premises. 
First, in mapping a day, each participant draws a line on a plan of the school to represent their movements on a typical day. Comments are added and colored stickers are used to indicate 'places that work' and 'places that do not work'. The aim is not only to gain an impression of the participants' movements and use of the school, although this can be interesting in itself (see [40] p. 13 for a notable contrast between movements of teacher and a student in a UK secondary school). The annotations, and resulting discussion between participants, also illuminate the intertwining of spatial, organizational, and cultural factors [41] that makes understanding a community's use of their space so challenging. Next, participants work in groups to 'diamond rank' photographs of learning environments, according to whether they represented a 'good place for learning' or a 'poor place for learning' (see Figure 1). The intention with this activity is to enable participants to connect their beliefs and values about education with spatial possibilities, addressing Halpin's critical comment that, 'thinking anew about spaces for learning cannot be sensibly commenced in the absence of deliberations about purpose' ([43], p. 251).

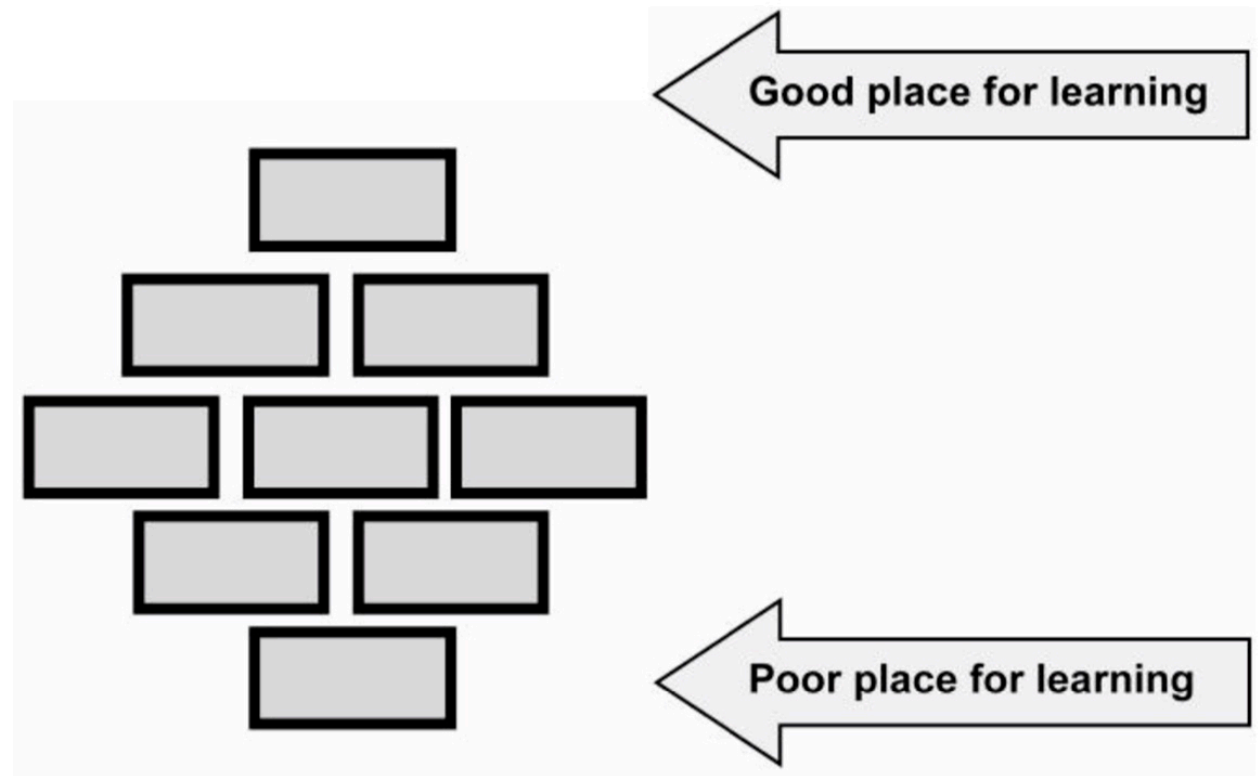

Figure 1. Instructions for 'Diamond Ranking' nine images according to opinions about suitability for learning.

The final activity calls for groups to produce ideas for development of the school premises, through a structured activity where they first choose two or three statements from a bank of suggestions answering the question 'What should be done here?' Using a variety of images and a plan of the school, they work together to create collages of needs and proposed solutions (see Figure 2). This structured approach to participatory design, making use of some provided materials and clear objectives, has been noted as succeeding with both adults and children through the provision of 'time and permission to pause and think' ([44], p. 8) with opportunities for movement, all underpinned by a focus to keep participants centered. 


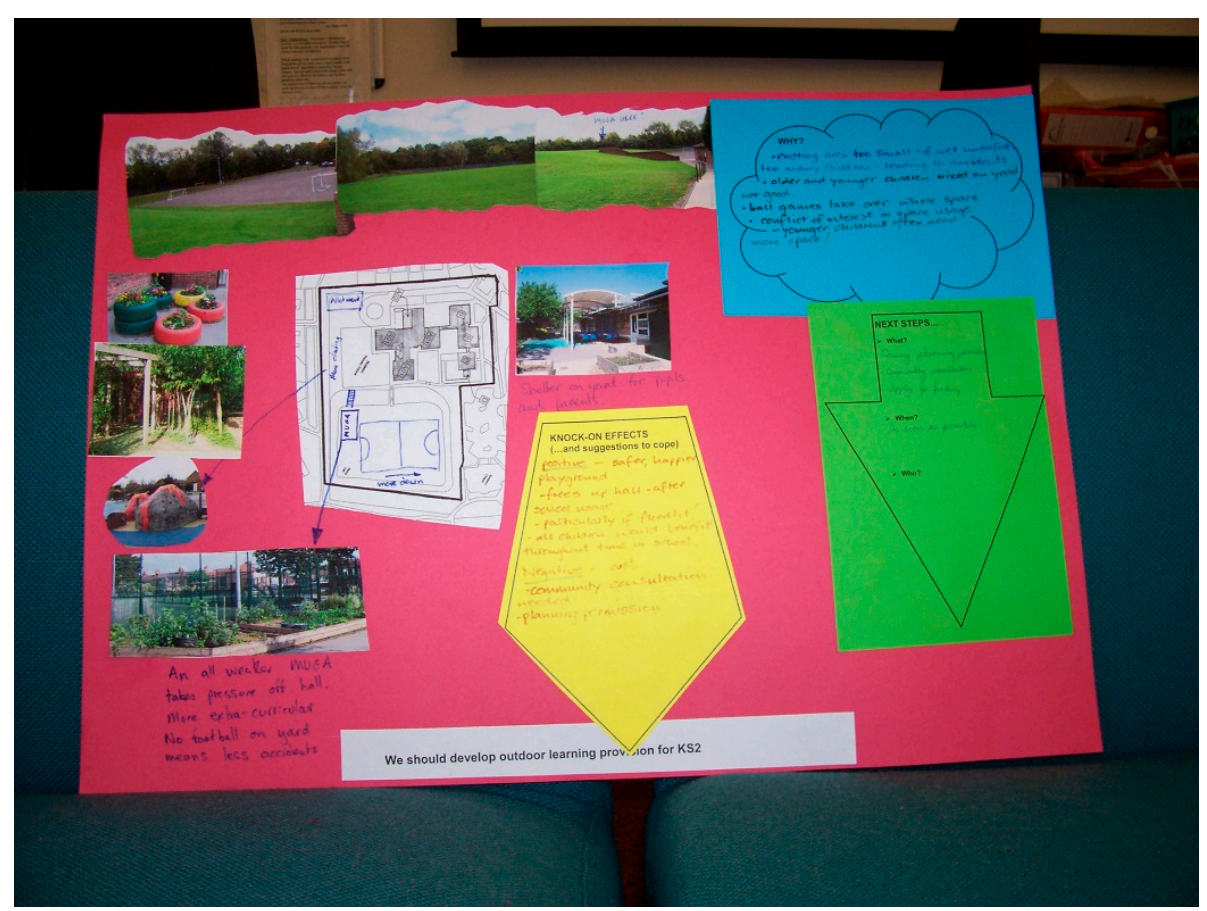

Figure 2. Collage presenting a priority for change and design suggestions from staff.

\section{Results: Use of the System within Two Contrasting Contexts}

\subsection{In England}

England has an educational system with power and decision-making distributed through levels of management from the individual school to the national government. During much of the 20th century, lots of control rested at the local (i.e., city or county) council level, with counties organizing and funding education in schools in a geographical area through local authorities (LAs). However, a series of education policy reforms in the late 20th and early 21st centuries, moved funding and control away from LAs [45]. This has resulted in a much more mixed provision of schools inside and outside the LA, 'multi academy trusts' chains of schools, 'free schools' answering directly to the national department for education, alongside the continued existence of faith schools with their own local structures. Although the extent to which the claimed intention of increasing autonomy for individual schools has been achieved is arguable, head teachers (principals) have become more aware of possibilities for school-level development.

This is the background to the invitation received in 2013 by the Centre for Learning and Teaching (CfLaT) team at Newcastle University from a newly appointed head teacher in a local primary school. The school was a LA school, and it was to this body that the head would need to appeal for funding for any refurbishment, but the head teacher was motivated by his own observations of the use of the school and funded a half-day staff workshop from the school's budget.

Built originally as a primary school (for children aged between 4 and 11), this was still the school's purpose, although there had been some additions and development of nursery space to accommodate 3-4-year-old children. At this time there were 411 children on roll in Reception to Year 6, mainly organized into two classes of approximately 30 children per year group, and the nursery facility. The premises date from the early 1980s, which was the beginning of a downturn in school building in the UK [46]. The school was built to serve a new community between former mining villages as part of a 'new town' and opened in 1980 with a small roll that grew rapidly as the local housing was built. Although quite traditional in external appearance, with brick walls and tiled, pitched roof, internally there were four semi-open plan learning spaces, with the few internal walls non-loadbearing. This original design had however, by 2013, been reconfigured to provide 
a mix of mainly enclosed classroom of differing sizes with some spaces used for class learning and circulation space.

During an initial half-day workshop, we facilitated the collaborative activities with school staff (including teachers, a school governor, teaching assistants, deputy and head, administration, and support staff). The 33 participants each produced an individual map (see Figure 3 for an example). Written comments showed appreciation of recent improvements in specific rooms and with newly refurbished toilets. The teaching spaces that were liked tended to be the self-contained classrooms, as opposed to the teaching spaces in open areas, which provoked more criticism. Teachers complained that these spaces were "noisy" if you were teaching or learning here but also worried about disturbing classes if they were passing through. Yet staff were also critical of the limited space in some of the enclosed classrooms. Mixed feelings were expressed about the various outdoor spaces. These ranged from inevitable issues with the outdoors ("mud"; "children hide in trees") through to assertions that some of these spaces could be much better used and should be developed. Specifically, some teachers expressed a desire for direct access to the outdoors from their classrooms, enabling more flexibility and spontaneity in how they use outdoor space for learning.

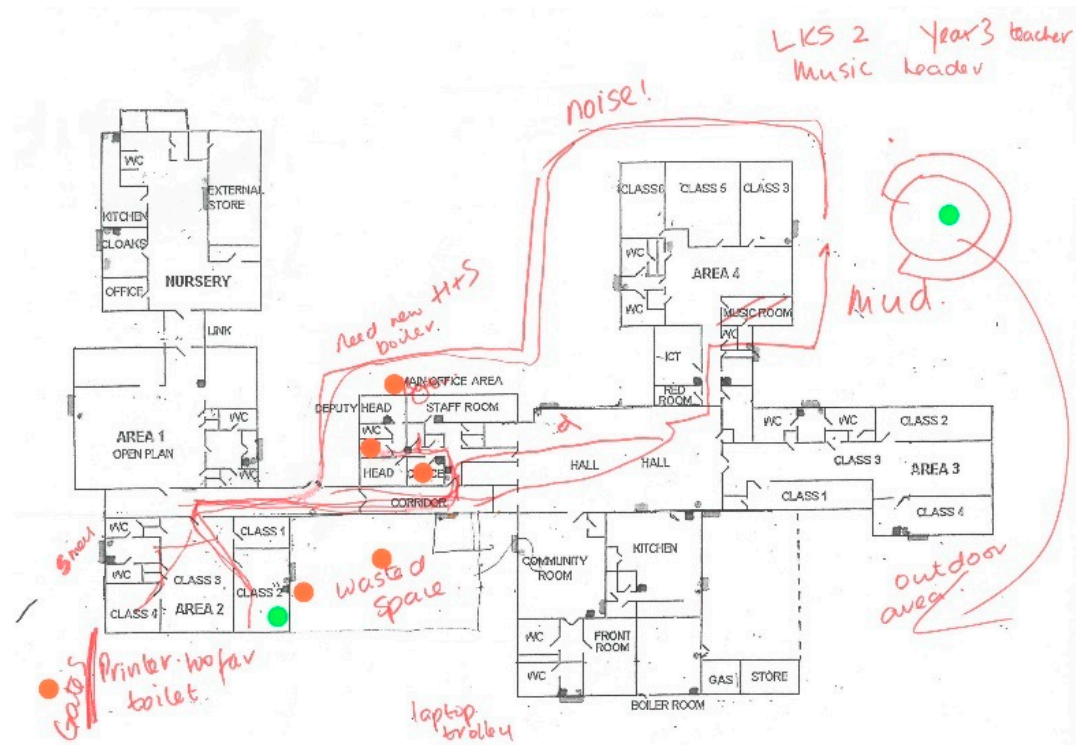

Figure 3. An example of a staff member's mapping of a typical day.

The second activity of diamond ranking by groups of staff, who, within their groups, had similar roles in the school, produced eight diamonds. These were then displayed for discussion between groups about what constitutes or contributes to a good educational space (see Figure 4). Ideas to emerge from the diamonds included the positive connotations for most staff of outdoor space for learning, although there was significant difference of opinion about what constitutes appropriate outdoor learning space. The indoor learning spaces were placed in very different positions by different groups, partly due to differences in the age of children they worked with. Wherever particular images were ranked, however, the accompanying comments suggested some shared values around providing appropriate spaces for different styles of teaching and to satisfy differing preferences of learners and teachers. Space to move, flexibility and having resources available to learners were also valued elements. The collages were very varied across the groups and were used by group members to initiate discussions between groups. Some consistent priorities emerged, however: reorganizing the location of classes of particular aged children, together with ideas for improving the entrance and outdoor spaces. 


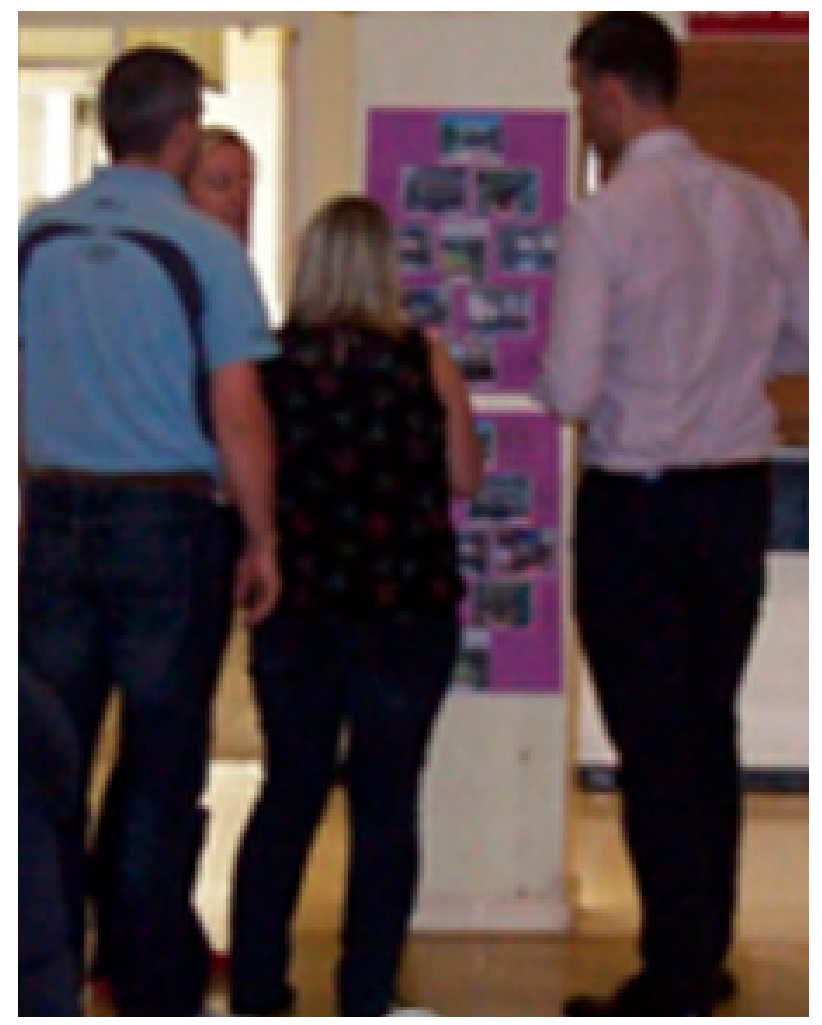

Figure 4. Staff discuss the diamonds the groups have produced.

We produced a report to the school, detailing what we had discovered about the use of the building and the views of the staff, as well as summarizing the ideas for change that had been generated. We went on to research the school use of space, working collaboratively with some of the teachers and including the student perspective. An outcome of these two phases of engagement was to produce a report to support the school's application to the LA for funding. The building work that was eventually completed in 2017 was based on a re-worked plan that accommodated some, but not all, of the design suggestions made.

Alongside these bigger changes in the school infrastructure, however, there were changes in how staff thought about school space. In the three and a half years that elapsed between the initial workshop and the building work, staff engagement with the environment was sustained and, in many cases, developed. In a visit during this period, we noticed that some organizational and spatial adjustments had been made within the existing physical environment. These included changes in the management of student arrival and departure, and rearrangement of furniture by teachers in two small, enclosed classrooms and within the unenclosed learning space to create usable 'carpet spaces'. Furthermore, the original LA architect's plan of providing a layout of enclosed classrooms, favored by teachers of the older children, quickly came to be seen by the head teacher and other staff as inappropriate for the younger children. The design for this block was redrawn to provide a mix of open and enclosed space.

It was this design, revised through discussions with the principal and teachers, that was built, and has been well-received by the staff. The enclosed classroom model was followed for the area for the slightly older students but included some adjustments to support the teacher communication and collaboration that was a benefit of the original school design. Staff reported that they were able to make suggestions through the planning and construction stages, such as aligning doors across a corridor to facilitate communication and circulation. 


\subsection{In Uruguay}

Uruguay's education system can be described as traditional and centralized. Decisions are taken at a central level by the National Public Education Administration (ANEP), the organization responsible for formulating and implementing policies in school education. Curricula for all schools are defined at this central level and there is little scope for public or private schools to exercise autonomy. However, private schools have certain freedom on decisions about their physical learning environments, though following the 'private schools building regulations' [47].

In this context, in 2018 the headteacher of a local private school in Uruguay approached the research team at the Faculty of Architecture, University ORT for advice on the design of a new building for the school. The plan was to build a new preschool to replace the existing one located in the original building from 1950 situated in a mid-to high-income area in the city of Montevideo. At this time the school had 900 students on roll between the ages of 3 and 18 years old, including preschool, primary and secondary levels mainly organized into three classes of approximately 30 children per year group. The new preschool would be designed to host up to 300 students aged 3 to 5 years old.

The intention with the design of the new preschool was, according to the school board's vision, to create an open and inspiring environment for preschool children making the most flexible use of the spaces. Directly linked to the educational vision to introduce progressive pedagogical ideas, the idea was to push for pedagogical change through the design of an innovative learning environment.

Firstly, a meeting was held with the preschool coordinator, teachers, and teacher assistants where the pedagogical change proposal for the preschool was presented as well as the need to support it with a new building that would sustain the change. The participants were very positive and interested in the change proposal. Aspects related to the daily use of spaces, positive and negative aspects of the existing building and possibilities for the new space were discussed. During the meeting, photos and videos were shown that served to exemplify different types of spaces, in addition to encouraging educators to think outside the box.

Secondly, a walkthrough of the existing building was carried out with observations of the use of the different spaces in the existing building by teachers and students and informal talks with several teachers and teacher assistants. These were documented through photos taken during the visit. During this visit issues with the length and dullness of corridors, the layout of the classroom spaces and the location and level of noise in the dining area were discussed.

Finally, a half day workshop to facilitate collaborative activities was held with teachers, educational specialists, and teacher assistants. The 18 participants each produced a map of their movements on a typical day (see Figure 5 for an example). Written comments showed appreciation for the outdoor area and the psychomotricity room. However, access to the outdoor area was highlighted as problematic as it overlaps with the entrance to the toilets. The distances between classrooms and the gym area were considered too long and interfering with the school entrance. The dining areas was marked as noisy and difficult to access. In groups, educators worked in diamond ranking nine photographs of learning spaces that were then displayed amongst the rest of the groups for discussion (Figure 6). These photographs showed examples of spaces for younger aged children reflecting (or challenging) local norms and cultures. During this stage, six diamond rankings were produced. The teaching spaces that were most liked tended to be the teaching spaces in open areas with nooks and niches and with movable furniture, while the enclosed classroom photo was ranked last. The same groups had to then work with two propositions on what to do in the new space to create a collage of the needs and the solutions, making sure that the 'Why', 'Effect' and 'Next Steps' were answered. Six collages were produced during the last activity (Figure 7). The propositions that had more collages stated the need to open the space and do more group teaching. Though the comments in the collages also indicate the need for teacher training and work in collaboration. 


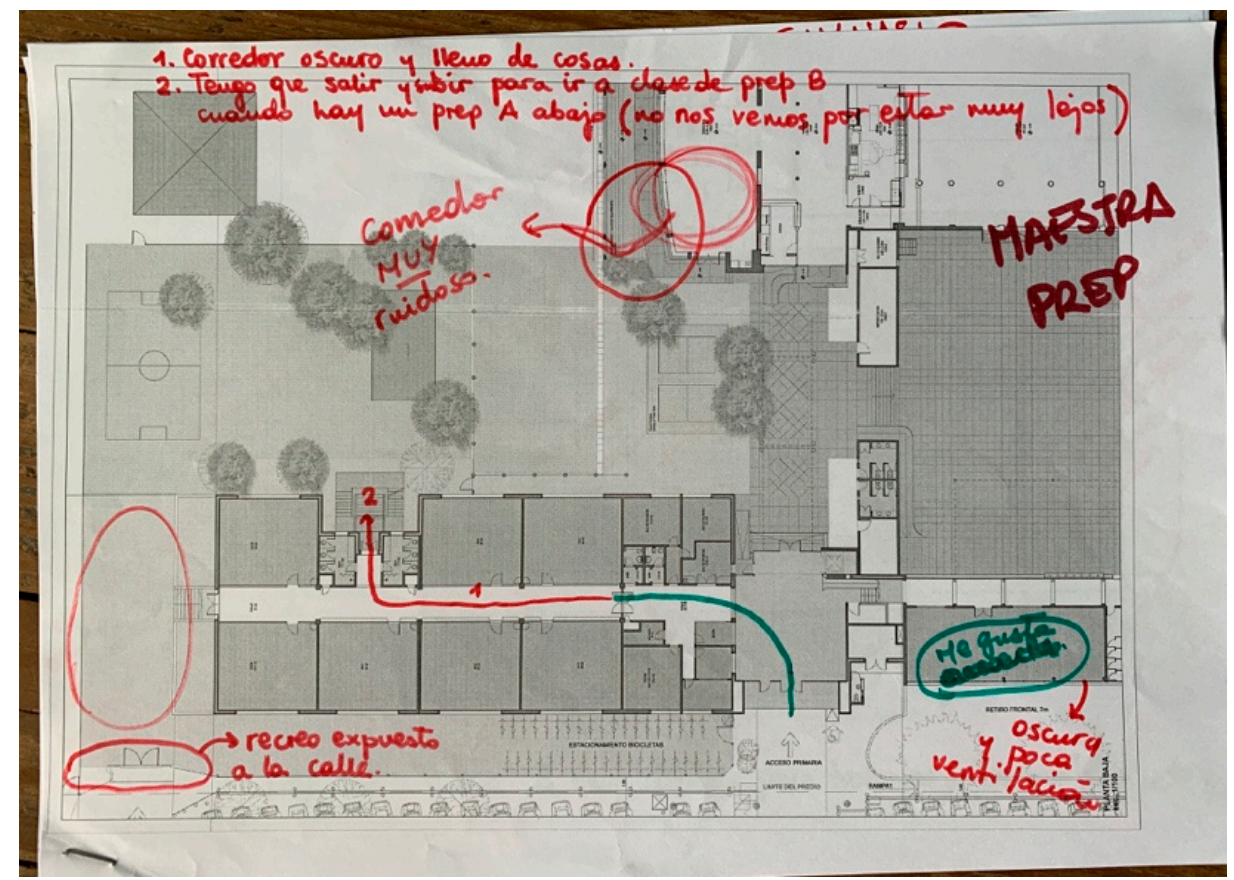

Figure 5. An example of a Uruguayan staff member's mapping of a typical day.

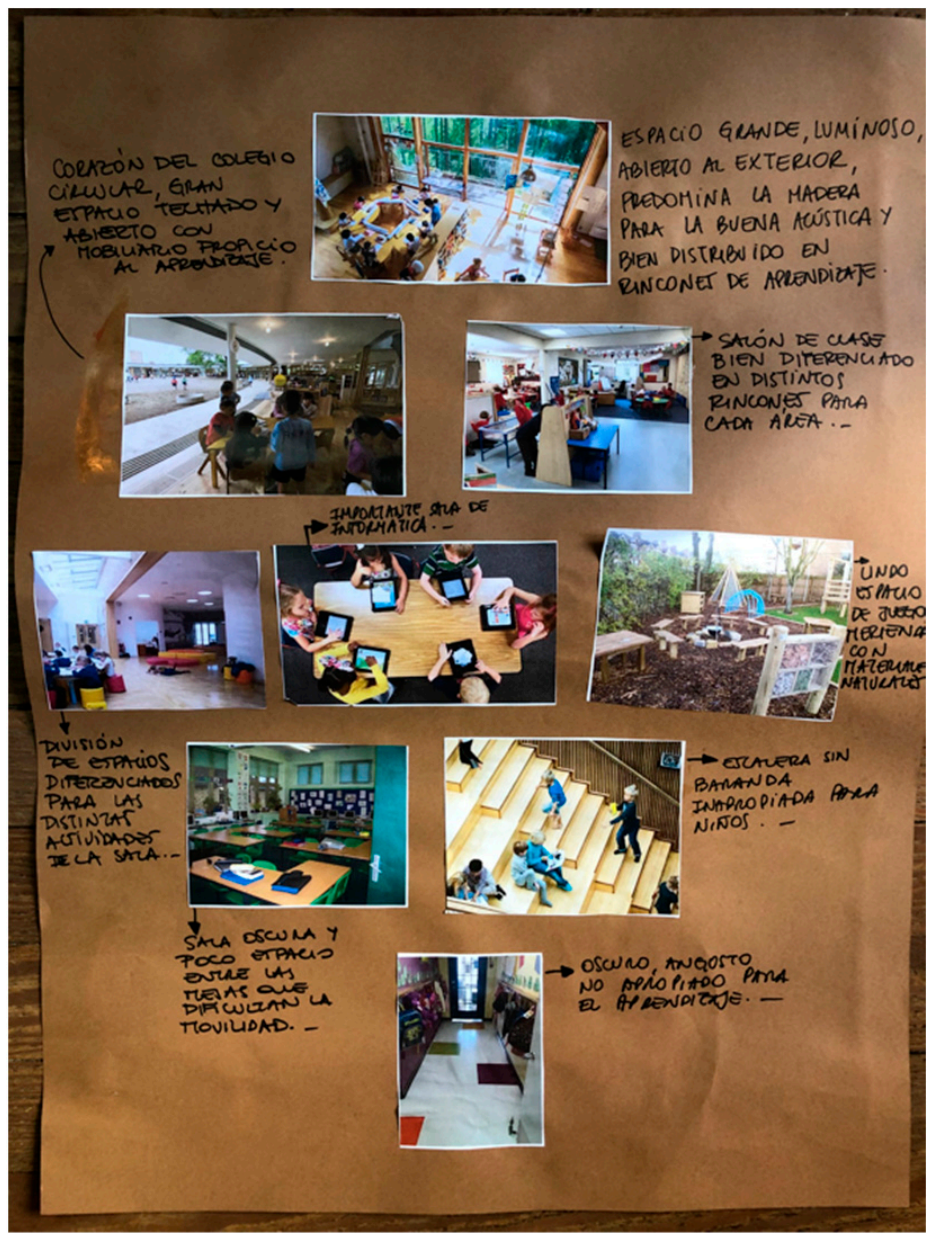

Figure 6. An example of the result of a diamond ranking exercise. 


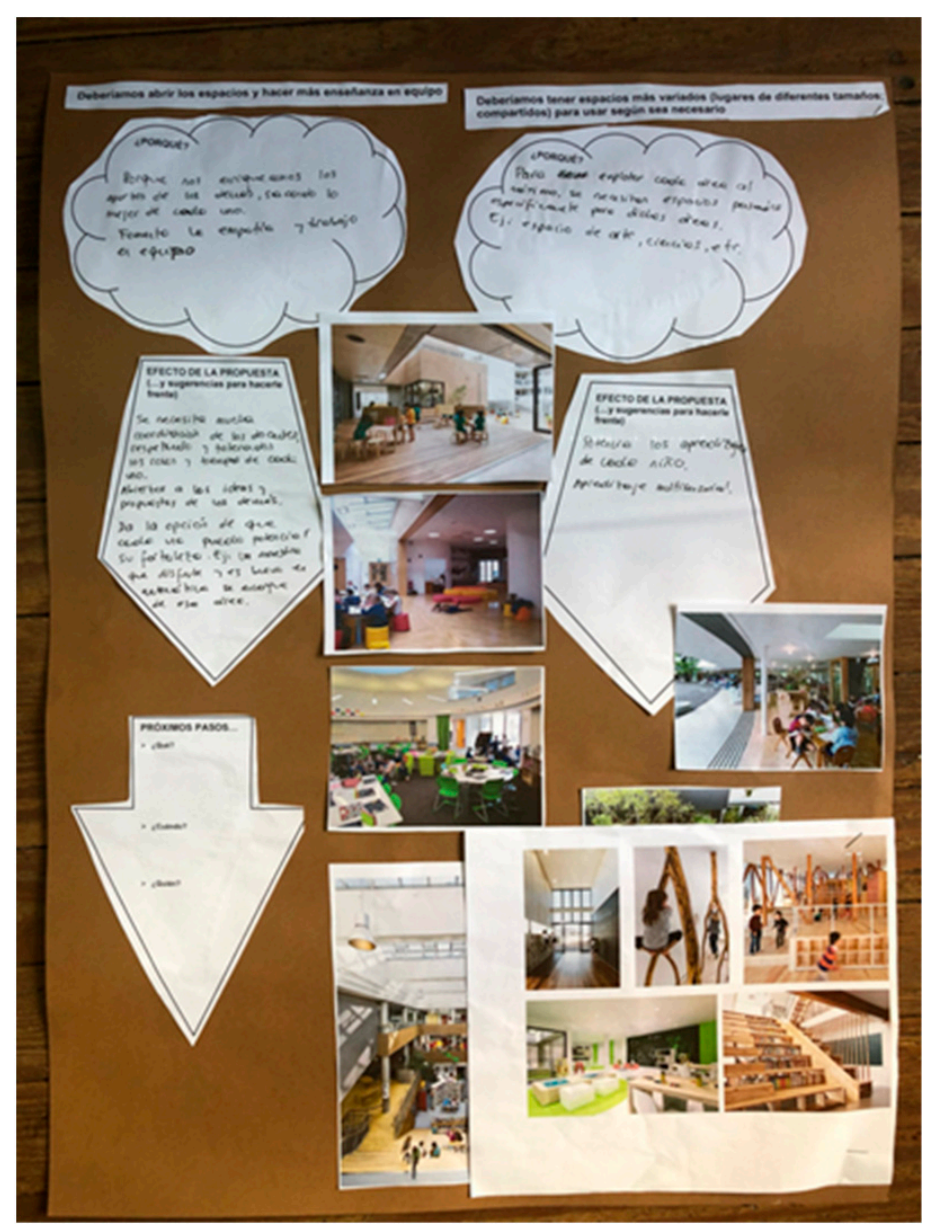

Figure 7. An example of a resulting collage by one of the groups.

A report with the findings was prepared for the school detailing what was found about the use of the existing building and the views of the teachers and staff considering its direct influence on the design of the new preschool space. The main findings show teachers' desire to break with the concept of "enclosed classroom" as well as an appreciation of the difficulties it entails, though seen as a positive change.

The original architects' plan with a layout of enclosed classrooms was redrawn in line with the report findings as it was seen by head teacher and school board as not appropriate. The new design for the preschool provided open and flexible spaces. During the construction process staff were offered various professional learning opportunities during after-school hours, including sessions with outside specialized speakers in line with the requests in the written comments during the workshop. Online learning resources were also made available. The coordinator also worked with the staff and experts to explore how to successfully use the space across a range of lessons.

\section{Discussion and Conclusions}

As evidenced above, the system for collaboration enabled, in both schools, the productive involvement of the school staffs in planning change to their educational spaces. They were able to engage at the time, building shared ideas and were able to convey these to the architects so that plans were adjusted. The participatory design process also led, in these two cases, to sustained collaboration between architects and educationalists through the construction stage and into use of the new spaces. There is also some suggestion, in these cases, of the educational staff, through their involvement in the design projects, developing their 'environmental competence' [33]. Given the considerable problems, outlined above, of transfer in education across cultures and nations, the fact that an approach developed in the 
UK context, and used initially in a primary school in northeast England, was also successful in a nursery setting in Uruguay is significant. Therefore, we will first consider the reasons for the success of our system in facilitating collaboration in the design of educational space in these two contexts before proposing some suggestions for how it was able to overcome the challenges of travel between them.

A fundamental reason why attempts at widening participation in planning the design and use of school space falter is the time such engagement and interactions require. Our system is quite quickly worked through since the activities can be completed comprehensively in a single session of 2-3 h. Additional time is required around the session to prepare the materials, informed by understanding of the context, and then to understand the resulting artefacts, in light of the conversations and discussions witnessed on the day. These associated actions, however, do not require more time from the professional educators and architects who are central to the collaboration, as long as the facilitator(s) of the workshop is independent of these groups. Such independence would be preferable, we argue, and this requirement for an external facilitator is indeed recommended for successful participatory design [34].

A strength of our system is that particular expertise, in either architecture and design or in education, is not required of the facilitator since the materials and activities convey some ideas and, more importantly, enable the professionals to draw on their own expertise. The mapping supports the educationalists to see their setting in spatial terms, while the images for the diamond rank and collages provide new ideas for furniture, layout and use of space. Thus, the process enabled the school staff to think visio-spatially about education, both in terms of their own practices and regarding possibilities for change. Meanwhile, the visual results of the workshops helped with conveying and sharing ideas, within the schools and beyond. In Uruguay, the architects appreciated the production of something they could translate into space, while, in England, it was observed that the teachers had more confidence to engage with the initial plans drawn up by the LA architect. The visual elements can be seen as a common language that can ease communication between designer and educator. It also helps with the travel of ideas since the different languages (Spanish and English in this cases) do not add to the difficulty of knowledge transfer, for example misinterpretations of educational or design ideas.

It appears that professionals are enabled to connect their knowledge across the disciplinary divide between education and architecture. The teachers feel that their voices have been heard, and therefore can have more certainty on what to expect as the end result. Their participation also contributes to the professional development of teachers that is advised to support their use of new, innovative spaces [32] and in order, more generally, to develop their 'environmental competence' [33] so that 'teachers to turn to material objects in full knowledge of the pedagogic possibilities they open up' ([35], p. 590).

This combination of activities that stimulate and activate existing knowledge, rather than requiring lots of prior learning, which can be facilitated by a non-expert and that are not excessively time-consuming, ensures that our system is manageable on each and every occasion that a school space is proving difficult to use or a rebuilding opportunity occurs. This practical utility is very valuable, given the need for interdisciplinary collaboration to occur each time [28] if the resulting design and use of the space is to be successful [26], avoiding mismatches between design intentions and actual use [22,25] that are expensive [48] as well as frustrating.

Some of the observations about the reasons for the success of our system are suggestive of why it was also able to travel, supporting collaborations over the design of educational space in two very different contexts. Essentially, its success is based on the fact that it is not educational or architectural ideas, policies or practices, that are being transferred, but instead the means for generating local ideas based on local knowledge. Rather than trying to transfer a project, we transferred the tool to enable participation in the project. This is a powerful approach, addressing the concerns discussed above about uncritical transfer of practices, curricula, and school buildings between differing contexts [16-18,20]. More 
generally, it also takes seriously the challenge outlined by Thomson and Hall for education research of managing the general and the specific, given that, "There are things about schools which are the same, just as there are things about all of them that are distinctive' ([49], p. 7, italics in the original).

Finally, it is worth noting that in supporting our educator participants to produce their own visual representations of educational activities occurring in re-imagined physical spaces with chosen material resources, which can be shared and discussed, we are countering the tendency so critiqued by Wood [20] for school leaders to seize on 'seductive' visual representations of settings for educational cultures and activities quite at odds with their own. The images that are provided to the participants can be chosen so that they are appropriate to their social, cultural and pedagogical assumptions, but while also ensuring there is a range for them to choose from so that they have representations of new and different settings and materials to consider. Thus, ideas for the design and use of schools, visually represented, will only travel internationally through being discussed and reinterpreted, by local architects and educators, rather than imposed on systems where they do not fit.

Author Contributions: Conceptualization, P.W. and P.C.; methodology, P.W. and P.C.; validation, P.W. and P.C.; formal analysis, P.W. and P.C.; data curation, P.W. and P.C.; writing-Original draft preparation, P.W.; writing - Review and editing, P.W. and P.C.; visualization, P.C. All authors have read and agreed to the published version of the manuscript.

Funding: This research received no external funding.

Conflicts of Interest: The authors declare no conflict of interest.

\section{References}

1. Lawson, B. How Designers Think. The Design Process Demystified, 4th ed.; Architectural Press: Abingdon, UK, 2005.

2. Lawson, B. Schemata, gambits and precedent: Some factors in design expertise. Des. Stud. 2004, 25, 443-457. [CrossRef]

3. Rosero, V. Modernity, guilty? The role of architecture in social housing. Pruitt-Igoe as a symbol. Rita 2017, 8, 126-135.

4. Nisivoccia, E.; Craciun, M.; Gambini, J.; Medero, S.; Méndez, M.; Nudelman, J. La aldea Feliz. Episodios de la modernización en el Uruguay; Ministerio de Educación y Cultura, Ministerio de Relaciones Exteriores, Universidad de la República: Montevideo, Uruguay, 2014; 342p.

5. Jamieson, P.; Fisher, K.; Gilding, T.; Taylor, P.G.; Trevitt, A.C.F. Place and Space in the Design of New Learning Environments. High. Educ. Res. Dev. 2000, 19, 221-236. [CrossRef]

6. Abassi, N. Pathways to a Better Personal and Social Life through Learning Spaces: The Role of School Design in Adolescents' Identity Formation, in Faculty of Architecture, Building and Planning. Ph.D. Thesis, University of Melbourne, Melbourne, Australia, 2009.

7. Malaguzzi, L.; Zini, M. Children, Spaces, Relations: Metaproject for Environment for Young Children; Ceppi, G., Zini, M., Eds.; Grafiche Rebecchi Ceccarelli: Modena, Italy, 1998.

8. Morgan, J. Critical pedagogy: The spaces that make the difference. Pedagog. Cult. Soc. 2000, 8, 273-289. [CrossRef]

9. Higgins, S.; Hall, E.; Wall, K.; Woolner, P.; McCaughey, C. The Impact of School Environments: A Literature Review; Design Council: London, UK, 2005.

10. Whyte, J.; Cardellino, P. Learning by Design: Visual Practices and Organizational Transformation in Schools. Des. Issues 2010, 26, 59-69. [CrossRef]

11. Hantrais, L. Contextualization in cross-national comparative research. Int. J. Soc. Res. Methodol. 1999, 2, 93-108. [CrossRef]

12. Alexander, R.J. Culture and Pedagogy: International Comparisons in Primary Education; Wiley-Blackwell: Malden, MA, USA, 2001.

13. May, J. A History of Australian Schooling. Hist. Educ. Rev. 2014, 43, 260-262.

14. Chisholm, L.; Leyendecker, R. Curriculum reform in post-1990s sub-Saharan Africa. Int. J. Educ. Dev. 2008, 28, 195-205. [CrossRef]

15. Khormi, S.; Woolner, P. Development of Saudi Mathematics Curriculum between Hope and Reality. Int. J. Manag. Appl. Sci. 2019, 5, 26-36.

16. Alexander, R. Evidence, rhetoric and collateral damage: The problematic pursuit of 'world class' standards. Camb. J. Educ. 2011, 41, 265-286. [CrossRef]

17. Auld, E.; Morris, P. Comparative education, the 'New Paradigm' and policy borrowing: Constructing knowledge for educational reform. Comp. Educ. 2014, 50, 129-155. [CrossRef]

18. Clapham, A.; Vickers, R. Neither a borrower nor a lender be: Exploring 'teaching for mastery' policy borrowing. Oxf. Rev. Educ. 2018, 44, 787-805. [CrossRef]

19. Uduku, O. The Nigerian 'Unity Schools' project: A UNESCO-IDA school building programme in Africa. In Designing Schools: Space, Place and Pedagogy; Darian, S., Willis, J., Eds.; Routledge: New York, NY, USA, 2017; pp. 175-187.

20. Wood, A. Built policy: School-building and architecture as policy instrument. J. Educ. Policy 2020, 35, 465-484. 
21. Sanoff, H. Designing a Responsive School: Benefits of a Participatory Process. Sch. Adm. 1996, 53, 18-22.

22. Gislason, N. The Open Plan High School: Educational Motivations and Challenges. In School Design Together; Routledge: London, UK, 2015; pp. 101-120.

23. Carvalho, L.; Yeoman, P. Framing learning entanglement in innovative learning spaces: Connecting theory, design and practice. Br. Educ. Res. J. 2018, 44, 1120-1137. [CrossRef]

24. Blackmore, J.; Bateman, D.; Loughlin, J.; O'Mara, J.; Aranda, G. Research into the Connection Between Built Learning Spaces and Student Outcomes; Education Policy and Research Division, Department of Education and Early Childhood Developmen: Melbourne, Australia, 2011.

25. Gislason, N. The Whole School: Planning and Evaluating Innovative Middle and Secondary Schools. In School Space and Its Occupation: Conceptualising and Evaluating Innovative Learning Environments; Alterator, S., Deed, C., Eds.; Brill/Sense: Amsterdam, The Netherlands, 2018.

26. Sigurðardóttir, A.K.; Hjartarson, T. The Idea and Reality of an Innovative School: From Inventive Design to Established Practice in a New School Building. Improv. Sch. 2016, 19, 62-79. [CrossRef]

27. Uline, C.L. Decent Facilities and Learning: Thirman A. Milner Elementary School and Beyond. Teach. Coll. Rec. 2000, 102, 442-460. [CrossRef]

28. Cardellino, P.; Woolner, P. Designing for transformation-a case study of open learning spaces and educational change. Pedagog. Cult. Soc. 2020, 28, 383-402. [CrossRef]

29. Woolner, P.; Clark, J.; Laing, K.; Thomas, U.; Tiplady, L. A school tries to change: How leaders and teachers understand changes to space and practices in a UK secondary school. Improv. Sch. 2014, 17, 148-162.

30. Parnell, R. Co-creative Adventures in School Design. In School Design Together; Woolner, P., Ed.; Routledge: London, UK, 2015; pp. 167-183.

31. Graue, E.; Hatch, K.; Rao, K.; Oen, D. The wisdom of class-size reduction. Am. Educ. Res. J. 2007, 44, 670-700. [CrossRef]

32. Imms, W. Innovative Learning Spaces: Catalysts/Agents for Change, or 'Just Another Fad'? In School Space and Its Occupation: Conceptualising and Evaluating Innovative Learning Environments; Deed, S.A.C., Ed.; Brill/Sense: Amsterdam, The Netherlands, 2018.

33. Lackney, J. Teacher Environmental Competence in Elementary School Environments. Child. Youth Environ. 2008, 18, 133-159.

34. Parnell, R.; Cave, V.; Torrington, J. School Design: Opportunities through Collaboration. CoDesign 2008, 4, 211-224. [CrossRef]

35. Mulcahy, D.; Cleveland, B.; Aberton, H. Learning Spaces and Pedagogic Change: Envisioned, Enacted and Experienced. Pedagog. Cult. Soc. 2015, 23, 575-595. [CrossRef]

36. Saltmarsh, S.; Chapman, A.; Campbell, M.; Drew, C. Putting "structure within the Space": Spatially Un/responsive Pedagogic Practices in Open-plan Learning Environments. Educ. Rev. 2015, 67, 315-327. [CrossRef]

37. Allen, L. 'Snapped': Researching the sexual cultures of schools using visual methods. Int. J. Qual. Methods Educ. 2009, $22,549-561$. [CrossRef]

38. Darbyshire, P.; Macdougall, C.; Schiller, W. Multiple methods in qualitative research with children: More insight or just more? Qual. Res. 2005, 5, 417-436. [CrossRef]

39. Harper, D. Talking about pictures: A case for photo elicitation. Vis. Stud. 2002, 17, 13-26. [CrossRef]

40. Woolner, P.; Clark, J.; Hall, E.; Tiplady, L.; Thomas, U.; Wall, K. Pictures are necessary but not sufficient: Using a range of visual methods to engage users about school design. Learn. Environ. Res. 2010, 13, 1-22. [CrossRef]

41. Niemi, R.L.M.; Kumpulainen, K.; Lipponen, L.; Hilppö, J. Pupils' perspectives on the lived pedagogy of the classroom. Educ. Rev. 2015, 43, 683-699. [CrossRef]

42. Prosser, J. Visual methods and the visual culture of schools. Vis. Stud. 2007, 22, 13-30. [CrossRef]

43. Halpin, D. Utopian Spaces of "Robust Hope": The architecture and nature of progressive learning environments. Asia-Pac. J. Teach. Educ. 2007, 35, 243-255. [CrossRef]

44. Wilkinson, C.; Carter, B.; Satchwell, C.; Bray, L. Using methods across generations: Researcher reflections from a research project involving young people and their parents. Child. Geogr. 2021. [CrossRef]

45. Ball, S.J. The Education Debate, 3rd ed.; The Policy Press: Bristol, UK, 2017.

46. Saint, A. Towards a Social Architecture; Bath Press: Avon, UK, 1987.

47. ANEP. Ordenanza 14. Normas de Habilitación de Establecimientos Privados de Educación; Administración Nacional de Educación Pública: Montevideo, Uruguay, 1995.

48. French, R.; Imms, W.; Mahat, M. Case studies on the transition from traditional classrooms to innovative learning environments: Emerging strategies for success. Improv. Sch. 2019, 23, 1-15. [CrossRef]

49. Thomson, P.; Hall, C. Place-Based Methods for Researching Schools; Bloomsbury: London, UK, 2017. 